\title{
Discussion on the Development of Our Country's Insurance Assessment Industry
}

\author{
Dai Changli $^{\text {a }}$, Chen Zanyu ${ }^{\text {, }}$ Li Jiaying ${ }^{c}$, and Li Juhan ${ }^{d}$ \\ Sichuan Agricultural University Chengdu, China

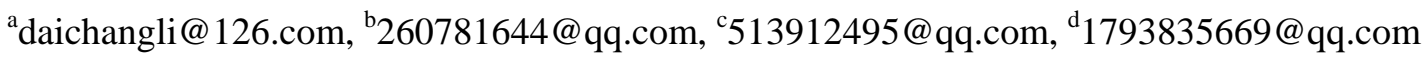

Keywords: insurance assessment; development status; suggestions.

\begin{abstract}
As an indispensable member of the insurance industry chain, insurance assessors play an important role in perfecting our country's insurance market system, improving market efficiency, safeguarding the legitimate rights and interests of insurance parties. With the insurance industry enters a critical period of transformation, the insurance assessment industry will also face more opportunities and challenges. This paper analyzes the development status of our country's insurance assessors through SWOT model, and in combination with the newly released regulations on Insurance Assessor Regulatory Provision, it puts forward suggestions on the development of insurance assessors from the aspects of talent system, business extension, insurance assessment report, operating conditions and regulatory system.
\end{abstract}

\section{Introduction}

On January 17, 2018, in order to further implement the Asset Appraisal Law of the People's Republic of China, strengthen the supervision of insurance assessment industry and regulate the operation of insurance assessment business, the Insurance Regulation Committee of China(for short CIRC) deliberated and passed the Insurance Assessor Regulatory Provision, which will be officially implemented from May 1. The new regulations put forward new requirements in terms of business rules, operating conditions, market exit, industry self-discipline, legal responsibilities, supervision and inspection. By analyzing the strength, weakness, opportunities and threats of insurance assessors in our country, this paper puts forward some suggestions by combining the characteristics of new regulations.

\section{Development status of insurance assessment industry}

\subsection{Strength}

Insurance assessors have strong professionalism and independence, and the current development situation is considerable.

In 2017, China's insurance industry realized a total insurance income of 365.801 billion yuan and set up 366 insurance assessment agencies. In the insurance market including insurance assessors, there has been a good development trend. As an important part of insurance intermediaries, the most obvious feature of an insurance assessor is its impartial position, which has the independence between the insurer and the insured. Due to information asymmetry, it is easy for the insurer and the insured to have conflicts in the claims process. Introducing the insurance assessor as a third part in the underwriting and claims section, it's not only conducive to solving the concerns of most insurance customers that the insurance is "one set for sell, and one for claims", and it's also beneficial to improve the efficiency and scientificity of claim settlement, improving the professional degree of the whole insurance market.

\subsection{Weakness}

The insurance assessment agency has a small scale, unreasonable business structure, lack of 
professional talents, and low acceptance in the insurance market.

Although China's insurance assessment industry is developing rapidly, the insurance assessment companies' registered fund that has already opened is generally the minimum prescribed by law, except for a few parts above 2 million yuan. Although the new regulations stipulate that the national institutional working capital is more than 2 million yuan and the regional institutional working capital is more than 1 million yuan, compared with foreign large-scale insurance assessment agencies, China' agencies have low establishment conditions, weak capital strength, and small scale, it is difficult to gain public trust. What's more, the employees of the insurance assessor lack professional technical background, and some begin to work only after a short period of training. Most of the assessors have less knowledge reserves and lack professional competence. With the development of modern technology and the rise of electronic networks, the insurance field has become more and more complex, involving financial, legal, management, manufacturing, transportation, machinery, chemical, electronics, construction and other high-tech fields such as aviation, satellite communications and so on. They are also playing an increasingly important role, and the boundaries of the industry have become increasingly blurred. At present, it is difficult for China's assessors to meet the requirements of professional and technical ability in the diversified fields.

In terms of business areas, China's current insurance assessment business mainly focuses on auto insurance, enterprise insurance, water insurance, construction insurance and other conventional insurance, especially the auto insurance assessment as the main service content, accounting for more than half of operating income. Limited resources in the industry focus on the low-end market, but for aerospace, petroleum, nuclear power, ocean-going fleets and other high-value, high-tech products are less involved.

\subsection{Opportunity}

China's insurance market has not been fully opened, insurance assessment industry has great potential for development.

On the one hand, with the continuous improvement of Chinese residents' living standard and education level, the society's understanding of insurance industry is also deepening, and the consumption of insurance products is becoming more and more rational. On the other hand, facing the risk loss brought by social economic activities and natural disasters, the public's demand for insurance and insurance assessment has become increasingly vigorous.

According to the data released by Swiss Re, in 2017, China's insurance density was $\$ 384$, with insurance depth of $4.46 \%$, and the world average was $\$ 650$ and $6.1 \%$, far lower than the average development level of international insurance industry. These differences reflect that China's insurance industry has a good growth prospect, and the development of insurance assessment industry is inseparable with the development of insurance industry. With the continuous expansion of insurance market, the substantial development of insurance assessment industry is just around the corner.

\subsection{Threat}

The insurance company and the international famous insurance assessors occupy the estimation market share, the domestic and foreign competition is increasingly fierce.

On the one hand, insurance companies always insist on implementing the business model of "one-stop" service to customers. Under the influence of this model, insurance companies not only do not attach importance to cooperation with assessment agencies, but take them as competitors to further reduce their living space. On the other hand, foreign-funded institutions started early and have strong advantages in advanced technology, abundant funds, high-quality talents, and their development is relatively mature. The threat of many competitors and potential entrants has long existed, so the development of insurance assessors faces strong resistance and competition. 


\section{Suggestions for the development of insurance assessment industry}

\subsection{Improve the insurance assessors’ professional quality and perfect the talent system.}

The new rules stipulate that insurance assessors include certified assessors and other assessors with professional ability, asset appraisal agencies are allowed to undertake insurance assessment. To a certain extent, the scope of insurance assessment practitioners has been expanded, which also means higher requirements for the professional ability of the assessors. With the continuous expansion of the insurance field, it is necessary for the assessment practitioners to skillfully master and use their professional knowledge, be able to correctly deal with difficulties in the assessment field and quantify relevant losses. On the one hand, insurance assessors should accelerate the improvement of the education system, formulate a scientific qualification examination system, implement regular assessment, and provide more career development impetus for assessors. On the other hand, a scientific and reasonable promotion mechanism and incentive mechanism should be established to prevent brain drain.

\subsection{Promote the expansion of insurance assessment business into emerging areas and achieve diversified development of assessment business.}

The extension of assessment business is to refine business categories and improve professionalism. on the one hand, insurance assessment can cover a wide range of areas at present. In addition to auto insurance with the largest business volume, other types of insurance, such as corporate property insurance, water insurance, offshore oil and some cutting-edge technology sectors, have increased demand for insurance assessment; on the other hand, the emergence of personalized and specialized service insurance, such as private family health insurance, endowment insurance and education enrollment insurance,which makes the professional requirements of assessing claims become higher and higher. it has become an inevitable requirement for the insurance assessment business to develop in the direction of "high grade, precision and advanced", Only by constantly mastering and applying new technologies, strengthening diversified cooperation with insurance companies can we achieve substantial development in the increasingly fierce domestic and international competition.

\subsection{Scientifically make assessment reports, reduce insurance disputes, and establish a good social reputation.}

In insurance practice, insurance dispute and insurance claim, the assessment report as the basis of loss assessment plays an important role. The content elements and form elements of the report must be strictly required, the evidence types and signing methods of the assessment report should be clarified. Insurance assessors should adhere to the principle of prudence, observe professional standards and ethics, show fairness and justice in procedures and entities, strengthen the credibility of the report, and improve the recognition degree of the assessment agency between the insurer and the insured.

\subsection{Standardize the market access and exit system of insurance assessors, and strictly stipulate operating conditions and rules.}

The establishment of the insurance assessment agencies must meet the formal requirements for the establishment of the Insurance Assessor Regulatory Provision. Strengthen the review of the illegality and integrity of shareholders and partners through the negative list. The CIRC and its dispatched institutions shall strictly implement record management, and formulating a clear and scientific exit procedure. The assessment institutions that violate laws or regulations and lose the principle of integrity must be forced to withdraw, so as to maintain the good reputation of China's insurance assessment industry. 


\subsection{Strengthen supervision in the process and afterwards, and establish a "Four-in-One" supervision system of insurance assessment}

Strengthen the regulatory responsibility of the CIRC, establish the penalty rule of insurance assessor, strictly prevent the occurrence of systemic risk; The registered insurance assessment institutions should strictly comply with the Asset Appraisal Law and the Insurance Assessor Regulatory Provision, implement the annual report system of the insurance assessment institutions, strengthen internal control from various aspects such as the company's organizational structure, business process, authorization approval, and financial management, establish a comprehensive internal control system; Strengthen social supervision through credit rating system and public opinion, and improve the company information disclosure system; The assessment institutions shall king to law, strengthen the self-discipline management and supervision of the insurance assessors, and constantly improve the level of specialization and professional self-discipline. Form a "Four-in-One" supervision system of government supervision, enterprise internal control, social supervision, and industry self-discipline to maintain the normal order of the insurance market.

\section{References}

[1] The Insurance Assessor Regulatory Provision [J]. State Council of the People's Republic of China, 2018 (13).

[2] Wang Yuhang, Wang Bin, Wang Yuhong. Correctly guiding the rational development of China's insurance assessment industry [J]. Business Times, 2007 (8): 91-91.

[3] Tong Qing. Reflections on the establishment of SMEs' assessment service platform [J]. Insurance Research, 2015(D09):18-21. 